\title{
Sobre la garantía judicial de los derechos ${ }^{1}$
}

\section{Perfecto Andrés Ibáñez}

En recuerdo de Claudio Movilla

\section{Cumpleaños en derechos humanos: siempre poco que celebrar}

Este trabajo tiene su origen en una intervención motivada por la celebración del quincuagésimo cumpleaños de la Declaración Universal de 1948. Por definición, el uso del verbo "celebrar" sugiere en el sujeto de la oración una actitud satisfecha, la propia de quien festeja. No diré que falten motivos para que quien en este caso hubiese oficiado de celebrante pudiera participar en tal estado de ánimo. Pues, que la Declaración Universal emergiera en el horizonte político y jurídico-cultural del mundo de finales de la década de 1940, conmocionado por la, entonces, reciente escenificación de la apoteosis de la barbarie que le había tocado vivir, fue todo un logro. Y que a cincuenta años de distancia siga siendo un punto de referencia, haya inspirado y continúe inspirando - aunque sea modestamente- prácticas de humanización de la convivencia, y sirva como autorizado paradigma para deslegitimar las que se orientan en sentido contrario, es algo que ninguna persona sensible, y más si jurista, debería dejar de valorar.

Pero al mismo tiempo es obligado decir que hablar de derechos humanos y de su garantía es tratar de una frustración. Una frustración que pertenece a la misma naturaleza de la cosa, porque la categoría de referen-

1 Este texto es la amplia reelaboración de una intervención oral en las jornadas organizadas por el Consejo General del Poder Judicial, con ocasión del $50^{\circ}$ Aniversario de la Declaración Universal de Derechos Humanos, los días 27-30 de octubre de 1998. Fue publicado en Claves de Razón Práctica, No 90, marzo de 1999. 
cia expresa un ideal, consagra un modelo, como tal, de imposible plena realización. Es así, no solo en virtud de consideraciones empíricas, ya que hay la suficiente experiencia acumulada como para tener por cierto que el ser humano va a seguir negándola a sí mismo en los demás. Sino también por razones conceptuales, puesto que en materia de derechos fundamentales, si resulta posible establecer un límite mínimo, un umbral sine qua non, el horizonte, incluso en el mejor de los casos, permanecerá siempre lejano. Y también abierto a nuevos desarrollos, a contenidos inéditos que, como ha sucedido en la parte positiva de esta historia - que es el lado positivo de la historia - podrían incorporarse merced al esfuerzo de quienes aspiran a dejar tras de sí un mundo más habitable.

La afirmación de que al juez nacional le incumbe una función de garantía de los derechos humanos expresa lo que, a simple vista, al menos entre juristas, resulta obvia. Pero se trata de una obviedad normativa. De un postulado recurrente de las cartas de derechos y del constitucionalismo actual, que podría ilustrarse, sin ningún trabajo, con un nutrido aparato de erudición jurisprudencial de todos los tribunales nacionales e internacionales. Algo a lo que renunció de antemano. Por otro lado, es un postulado al que acontecimientos recientes han dotado de nuevos riquísimos perfiles, a los que sí referiré.

Así, pues, el título de intervención contiene, una realidad, una proposición prescriptiva: «El juez nacional debe ser el garante de los derechos humanos». Pero lo obvio del enunciado no debe tomarse como indicativa de la aproblematicidad de su contenido. De este forma parte una compleja gama de implicancias que expresan otras tantas exigencias, dirigidas a la política y al derecho; cuya realización aparece condicionada a la concurrencia de una articulada serie de presupuestos de diversa índole y cuya prestación exige, a su vez, un fuerte compromiso ideal incompatible con actitudes pragmáticas a favor de las que es sabido, militan viejas y elaboradas razones de realpolitik muy asentadas en un difundido sentido común. Muy común, también entre los operadores del derecho.

Con todo, lo cierto es que el imperativo deóntico que impone al juez nacional la prestación de esa relevante garantía existe como tal y es de una vigencia y de una validez indiscutible. Hoy forma parte del deber ser constitucional del derecho, que así incorpora estructuralmente un momento de tensión, una dialéctica interna en su propia realidad normativa.

Por otra parte, a estas alturas se cuenta con información suficiente y lo bastante contrastada para sostener que la existencia de una garantía juris- 
diccional de un determinado estándar de calidad es condición necesaria, aunque no suficiente, para que los derechos humanos puedan gozar de algún grado estimable de realización práctica.

\section{Derechos humanos y «constitucionalismo emancipador»}

Derechos humanos son hoy los derechos fundamentales, es decir, los que constituyen la condición de persona y que, por eso, corresponden universalmente a todos los seres humanos. Esta idea está - programáticamente - en la raíz del primer constitucionalismo liberal, le ha acompañado en todas sus vicisitudes posteriores y ha pasado a ser el núcleo mismo del constitucionalismo actual, que la ha dotado de consistencia positiva y de nuevos horizontes. Horizontes necesariamente abiertos, entre otras cosas, a la incidencia de la multiculturalidad, indudablemente llamada a introducir un contrapunto enriquecedor al marcado eurocentrismo de las actuales cartas internacionales de derechos.

Pero lo cierto es que, por debajo de esa continuidad aparente en la materia, el constitucionalismo surgido a partir de la segunda posguerra, aporta un importantísimo elemento de ruptura en positivo con la precedente forma de tratamiento de la cuestión de los derechos como objeto de regulación constitucional. Tanto es así que Di Giovine y Dogliani se han referido a aquel como promotor de una "democracia emancipadora", resultado de un tipo de textos fundamentales que no solo garantizan, al hacerlos positivos, los derechos civiles y políticos tradicionales, sino que incorporan, con los derechos sociales, un proyecto que compromete a todos los poderes con la realización empírica de una sociedad tendencialmente igualitaria.

Así, se verifica el paso de la constitución programa o la constitución marco, a la constitución ordenamiento a norma jurídica, que es también constitución-tarea (Gozzi). De este modo se pasa de un Estado legislativo de derecho a un Estado constitucional de derecho, que es Estado de derechos.

En el Estado del constitucionalismo liberal el componente "de derecho» se resumía en la primacía de la ley. Y el momento democrático en la omnipotencia de la mayoría u omnipotencia del legislador. En él era evidente la radical autonomía de la política y, como consecuencia, la precariedad de la garantía jurídica. 
No es una casualidad que el cambio de paradigma constitucional se presente en la escena histórica como una forma de reacción a la crisis de la democracia representada por la experiencia de los fascismos. Ni que ese constitucionalismo normativo se postule como un modo de asegurar el futuro de la democracia, precisamente, mediante el reforzamiento del componente «de derecho" que implica la rigidez constitucional.

Los derechos fundamentales dejan de ser una suerte de punto de referencia externo para constituirse en "fundamento funcional de la democracia», según señala Häberle, porque es solo "a través del ejercicio individual de los derechos fundamentales como se realiza un proceso de libertad que es elemento esencial de la democracia".

El reconocimiento jurídico de que pasan a ser objeto, hace de los derechos "la esfera de lo indecidible» (Ferrajoli), es decir, un límite de derechos democráticamente impuesto a la mayoría, o sea, a la política, en garantía de la democracia, que no es concebible sin el aseguramiento de una esfera de autonomía individual a sus protagonistas. Es también este autor quien se ha referido a los derechos fundamentales en esta versión como «las leyes del más débil», y es que, por primera vez en la historia, aquellos han salido del terreno de la metáfora para constituirse en elemento central y fundacional del Estado y del ordenamiento democrático. Integran «la dimensión sustancial de la democracia» (Ferrajoli), dan sentido a la política y al derecho y son su paradigma de legitimación. Y de deslegitimación, por tanto.

\section{Estado constitucional de derecho y jurisdicción}

El ordenamiento jurídico resultante del nuevo constitucionalismo experimenta cambios de relevancia en su estructura y en su dinámica interna, que afectan intensamente al papel de la jurisdicción y del juez. El primero y esencial es que la constitucionalización de los derechos fundamentales como vínculo al poder legislativo se traduce de inmediato en un nuevo sentido de la validez de la legislación ordinaria. Como ha señalado Ferrajoli, en oposición al tradicional paradigma positivista, la validez no es una simple connotación o un valor implícito en la mera vigencia de los actos normativos. La validez tiene que ver con el significado de estos, es una cuestión de coherencia o compatibilidad de las normas producidas con las disciplinas en un plano de superioridad su contenido material. La 
validez, en la nueva lógica del ordenamiento, no es ya un dato apriorístico, sino una cualidad solo predicable de la norma después de un juicio, que el legislador constituyente ha puesto a cargo del juez-intérprete. El patrón sustancial conforme al que se lleva a cabo el control de validez está integrado por los fundamentales: parámetros de legitimidad, por tanto, del derecho aplicable. Y, como luego veremos, parámetro de legitimidad, también, de la actuación jurisdiccional misma.

Este paradigma implica, pues, no solo un cambio en la relación legislador/ley-juez, sino que produce consecuencias relevantes en el plano de la legitimación de la jurisdicción y de la independencia judicial. En este modelo constitucional, puede decirse, encuentra el que hasta la fecha es su máximo de realización el desideratum contenido en el Art. 16º de la Declaración de derechos del hombre y del ciudadano de 1789: "Toda sociedad en la cual la garantía de los derechos no está asegurada, ni la separación de poderes establecida no tiene Constitución».

En efecto, mientras, por un lado, los derechos fundamentales se convierten en una esfera de derecho destinada al poder, en una suerte de derecho positivo sobre el derecho, para el legislador, por tanto, en primer término. Por otro, se rediseña la institución judicial, a la que se atribuye como cometido primordial la garantía erga omnes de la efectividad de aquellos, por eso la independencia.

En tal planteamiento hay algo de implícita redistribución de competencias y también una atribución condicionada de sentido tanto a la legislación como a la jurisdicción. Gozarán de él, es decir, de legitimidad como poderes en tanto y solo en la medida en que cumplan con fidelidad el papel constitucionalmente asignado.

Semejante criterio de legitimación a través de los derechos tiene una peculiar complejidad. De un parte, se presenta con una cierta valencia antimayoritaria: los derechos que se trata de garantizar son, por antonomasia, los de la parte débil, del individuo, del disidente, del imputado y deben serlo frente al poder antonomasia, el de la mayoría política. Pero, al mismo tiempo, si esos derechos se construyen como imperativo jurídico, es porque son el presupuesto de la democracia política misma. En efecto, ésta solo puede existir sobre la base de una ciudadanía integrada por sujetos cuya autonomía individual esté bien garantizada, en el plano normativo y en el de la efectividad de las normas.

En el modelo, con muy diversas calidades de realización práctica, el corolario de la atribución del indicado papel constitucional a la jurisdic- 
ción es un reforzamiento cualitativo de la independencia, con el correspondiente soporte institucional. Reforzamiento que, por primera vez, contempla de manera expresa la doble vertiente - externa e interna- de ese valor e implica la exigencia de rescindir la vinculación del juez al ejecutivo, propia del sistema napoleónico de organización judicial, por lo que tiene de negación del principio de sujeción del juez solo a la ley.

Sujeción solo a la ley (que es la ley más Constitución), pero, inequívocamente, a la ley. Cierto que la Constitución impone una lectura crítica de aquella, pero tal lectura deberá de ser intelectualmente honesta, rigurosa en el uso de las normas del discurso racional y técnico-jurídico y dotada del máximo de transparencia en la justificación.

Es asimismo cierto que la sujeción en exclusiva a la ley como garantía de derechos puede dar lugar a que, en ocasiones, la decisión judicial entre en colisión con posiciones políticas coyunturales de mayoría. Pero de esta posibilidad, que corresponde a la fisiología del sistema constitucional, no cabe derivar la atribución al juez de una función política de contrapeso en sentido propio. Porque el juez no es intelocutor sistemático del poder político y tampoco su fiscalizador permanente. Sus actuaciones precisan del impulso externo y se producen caso por caso. De ahí que, solo podría hablarse de contrapeso judicial en el sentido de que el poder judicial, esto es, la jurisdicción, debe estar siempre en condiciones de enjuiciar con eficacia una concreta actuación de poder que afecte a derechos, cuando concurra el supuesto de hecho legalmente habilitante y la necesaria demanda de intervención.

\section{La garantía judicial en la economía de los derechos}

Ya he señalado que los derechos fundamentales encarnan un modelo que, en cuanto tal y como abierto siempre a nuevos contenidos eventuales, está condenado a padecer un no despreciable grado de frustración. Con todo, no cabe duda que el constitucionalismo actual supone un paso significativo, en lo que se refiere a las condiciones de posibilidad de la efectividad de la garantía de aquellos, respecto del constitucionalismo liberal. En este, los únicos derechos consagrados, los de la primera generación, claros en la formulación normativa padecían seriamente por la notable precariedad de la garantía jurídica.

Esto es, seguramente, lo que llevó a los teóricos y, en general, a los juristas a asimilar de manera intuitiva efectividad a existencia en materia 
de derechos fundamentales; a considerar que allí donde no estuviese asegurada la posibilidad de realización y la reacción frente a las violaciones, el déficit no era solo de protección, sino, por así decirlo, ontológico: no había derecho donde no hubiera garantía institucional.

Tal es el punto de vista de autor tan significativo como Kelsen, para quien no existe el derecho sin el cumplimiento del correspondiente deber por parte de quien se encuentra obligado; pues "tener un derecho subjetivo significa [...] tener el poder de tomar parte en la generación de una norma jurídica individual por medio de una acción específica: la demanda o la queja». Y, todavía con más claridad, Danilo Zolo: «un derecho formalmente reconocido pero no justiciable -es decir no aplicado o no aplicable por los órganos judiciales mediante procedimientos definidoses, tout court, un derecho inexistente».

Semejante concepción ha pasado incluso a formar parte de un cierto sentido común de cultura jurídica, que incluye el cuestionamiento de la juridicidad de los derechos consagrados por las cartas internacionales, como consecuencia de su imposible justiciabilidad. Déficit este extensible a los derechos sociales, a los que de la misma manera se suele considerar también aquejados de una conocida precariedad jurídica.

El planteamiento tiene una inteligente proyección en la obra de Häberle. Para este autor, la exigencia de que «el hombre (no solo el ciudadano) debe ser tutelado de forma óptima frente a las amenazas para su libertad, conduce necesariamente, en las actuales condiciones, a los «derechos fundamentales como garantías procesales»». O lo que es lo mismo: «la afirmación y la tutela procesal de un derecho fundamental pertenecen a su "esencia» [...] la idea de una efectiva tutela jurídica procesal se ha añadido al «contenido esencial» del derecho fundamental».

La propuesta es inicialmente sugestiva y, al menos en una primera aproximación, parece la más coherente con la relevancia que la garantía jurisdiccional de los derechos adquiere en el vigente constitucionalismo. Según esto, la incorporación del momento de tutela a la propia naturaleza del derecho objeto de ésta, atribuye a la primera una dignidad sustancial, la calidad de verdadera condición sine qua non, y no del disfrute en los casos en que este resulte impedido por alguna acción obstativa, sino de la propia existencia del derecho como tal.

Pero, como señala Ferrajoli, en ese punto de vista del sentido común hay un engaño: lo que gana en relevancia el papel de la garantía, lo pierde, paradójicamente, el derecho mismo, que será débil en su realidad norma- 
tiva donde aquella sea débil, se inexistente allí donde no se dé. Hasta el punto de que, concluye el mismo autor, «si confundimos derechos y garantías resultan descalificadas, en el plano jurídico, las que son las más importantes conquistas del constitucionalismo de este siglo: la internacionalización de los derechos fundamentales y la constitucionalización de los derechos sociales, reducidas una y otra, en defecto de garantías adecuadas, a simples declamaciones retóricas o, a lo sumo, a vagos programas políticos jurídicamente irrelevantes».

La crítica de este autor encuentra fundamento en la propia naturaleza del orden jurídico. En los sistemas normativos nomostáticos como la moral, la existencia del derecho implica la de la correlativa obligación, por simple deducción racional; los sistemas nomodinámicos, como el orden jurídico-positivo, en cambio, se realizan de manera diacrónica; en ellos cada norma debe ser concretamente producida, de tal manera que la proclamación constitucional o legal del derecho lo constituye normativamente como tal, le dota de existencia, le crea como derecho. Pero solo como derecho si no se produce mediante otro acto normativo la predisposición del correspondiente mecanismo de garantía.

Ahora bien, tratándose de ordenamientos constitucionales de constitución rígida, como el español, el establecimiento de la garantía no queda librado al arbitrio del legislador: los derechos proclamados como fundamentales representan una obligación para él. Y esto sucede porque la enunciación normativa equivale al acto de creación de tales derechos por el legislador constituyente y a la generación del deber correspondiente a cargo del legislador ordinario. Si este omite la actuación debida no compromete la existencia del derecho como tal, blindado por su naturaleza de fundamental, sino que - concluye Ferrajoli- abre una laguna en el tratamiento de su desarrollo.

No faltará, tal vez, quien piense que al razonar así se incurre en un exceso de sofisticación, puro ejercicio teórico, sobre todo, cuando se trata de derechos que en el statu quo legislativo actual gozan ya de la correspondiente tutela. Es el caso de los derechos civiles y políticos, respecto de los que la propuesta de Häberle parecería que produce un efecto de reforzamiento. Pero la distinción que se propugna, además del rigor teórico, tiene, en general, claros efectos prácticos especialmente visibles en casos como el de los derechos sociales. Para éstos, la consagración constitucional, en defecto de justiciabilidad, al implicar la inexistencia, carecería de toda relevancia jurídica. O lo que es lo mismo, en términos prácticos 
la asimilación de derecho y garantía no añadiría nada allí donde ésta ya concurre; mientras que cerraría el paso a toda posibilidad de garantía efectiva donde ello no sucede. En efecto, pues el juez que, en presencia de un derecho de indudable existencia normativa, aunque legalmente no garantizado de manera suficiente, tendría motivos para sentirse interpelado por una eventual exigencia de tutela; donde el derecho — por el defecto de éstano existiera, carecería de toda razón jurídica para sentirse concernido.

De lo expuesto se sigue que la tutela jurisdiccional de los derechos no forma parte del contenido de éstos, sino que es, a su vez y por disposición constitucional, un derecho fundamental. Pero un derecho fundamental por derivación, en la medida en que resulta necesario para la efectividad de aquellos.

Y es un derecho de peculiar configuración: «derecho a organización y procedimiento" en expresión de Alexy, puesto que su prestación eficaz requiere la predisposición por parte del Estado de una legalidad procesal y de la adecuada infraestructura burocrática de personal y medios.

\section{Derechos Fundamentales, estatuto y cultura del juez}

La incorporación de los derechos fundamentales a la legalidad positiva produce efectos de singular relevancia en la esfera del juez. De una parte, como ya se ha anticipado, refuerza, en el plano de la legitimación, el fundamento de la división de poderes y de la independencia de aquel y, por otra, y correlativamente, comporta una evidente profundización del sentido de las garantías, tanto orgánicas como procesales. Las primeras, son presupuesto de la adecuada prestación de las segundas, las propiamente jurisdiccionales. Unas y otras operan en niveles formalmente diferenciables del universo judicial, pero se hallan en una relación estrecha de implicación recíproca y son función exclusivamente de los derechos que se trata de tutelar.

El juez del Estado liberal, juez sin constitución, con un status de objetiva subordinación política al ejecutivo, no necesitaba de otra legitimidad que la, apriorística, implícita en la formalidad de la investidura, y ejercía su función en un marco sin referencias constitucionales; el juez de nuestro ordenamiento debe revalidar su legitimidad — caso por caso - aplicando de manera independiente la ley válida, en un contexto de precisas exigencias procesales de relevancia constitucional. 
Emerge, así, con carácter prescriptito un paradigma de legitimación del juez de carácter material o sustancial, que es implicación directa del rango normativo de los derechos fundamentales, y que tiene proyección, al menos, en tres sentidos, con la correspondiente contrapartida de deber profesional.

El primero se concreta en el aludido imperativo de lectura crítica de la ley para verificar su compatibilidad sustancial con la Constitución. El segundo lo hace en la obligación de observar escrupulosamente las garantías procesales en que se traduce el derecho fundamental a la tutela judicial, que son cautelas frente al propio juez. El tercero en la obediencia al deber de motivar la decisión, para asegurar tanto la racionalidad en el uso del poder que mediante ella se ejerce, como la adecuada comprensión de su fundamento real por terceros.

Estos tres deberes constitucionales - se insiste que dados en garantía de los derechos fundamentales - operan, en caso de incumplimiento, como factores de deslegitimación. Porque la legitimidad del ejercicio jurisdiccional ha dejado de ser un a priori, una calidad forma-trascendente que acompañe siempre, para convertirse en resultado eventual, condicionado a la calidad de la actuación; y, en consecuencia, solo predicable en virtud de una valoración expost de ésta.

La constatación de este cambio de paradigma en el orden de la legitimación, plantea requerimientos en materia de independencia. Si esta tiene toda su razón de ser en el aseguramiento de la obediencia a la ley válida, habrá de implicar — dicho con Borré- la desobediencia a todo lo que no sea el imperativo legal. De aquí se derivan precisas exigencias culturales, de actitud y de sensibilidad. Y, desde luego, la ruptura reflexiva con un viejo y actual, antimodelo. El de cierto juez, tan hermético y distante en sus relaciones con el justiciable, como naturalmente abierto a las sugestiones políticas del establishment, sobre todo si estimuladas mediante contraprestaciones de carrera. Ese juez, al que según Casamayor no habría necesidad de comprar, puesto que bastaba con producirlo en una cierta clave. Hoy diríamos que programarlo de una determinada manera.

Así, pues, la estricta funcionalidad de la jurisdicción a la efectividad de los derechos fundamentales requiere la adecuada prestación de ese deber fundamental-medio que es para el juez la tutela judicial. Hacerlo en condiciones, demanda idealmente la concurrencia de esas «virtudes judiciales" a que se ha referido Manuel Atienza, de difícil plasmación normativa y más bien fruto posible y deseable de un clima cultural que habría de 
promoverse reflexivamente con esfuerzo sostenido. Pero requiere, asimismo, compromiso deontológico del juez con traducción en el cumplimiento satisfactorio de los deberes profesionales legalmente establecidos, mucho más concretos. Cuando tal compromiso no informe eficazmente la práctica del juez, el dato debería tener la necesaria repercusión negativa en las expectativas profesionales que dependan de una decisión discrecional del Consejo General. Y, en los casos graves, dar lugar a un ejercicio riguroso de la disciplina directamente orientado - diría que exclusivamente orientado- a asegurar la prestación de tales deberes. Esto último remite a un problema que no se encuentra bien resuelto ni en la legislación ni en la experiencia y que implica una delicada cuestión de límites: el hasta dónde de la intervención administrativa sobre una actividad como la jurisdiccional que debe responder al principio de independencia. Aunque hay un espacio cierto en el que debe operarse con energía cuando sea necesario, en la realidad no siempre acontece; al tiempo que no son inusuales en el órgano de gobierno de los jueces las inclinaciones a un cuestionable uso ejemplarizador de la disciplina, dirigido a incidir sobre actos o actitudes no estrictamente profesionales; sobre todo, en algunos asuntos estridentes de relevancia política y mediática.

En todo caso, es evidente que el juez garante solo puede ser resultado de la concurrencia de una doble condición de posibilidad. A saber, que él mismo se encuentre suficientemente garantizado en su independencia y que, a la vez, existan efectivas garantías frente a él en las actuaciones que protagonice.

Un Juzgado de ejecutorias de Madrid, hace apenas unos meses, al informar en un recurso de queja, justificaba una más que, ya a prima facie, discutible negativa a sustituir la pena de prisión, con el argumento de que la decisión correspondiente había sido adoptada en el uso de lo que constituye "una libertad discrecional del juez». El caso es singular por la franqueza y la elocuencia de la expresión. Repárese en la intolerable filosofía de la jurisdicción que subyace a ese modo de expresarse, que, a mi juicio, no permite el fácil consuelo de la hipótesis del supuesto aislado. Pues esa filosofía recurre en todas las ocasiones en que se dan motivaciones herméticas, autodefensivas, lamentablemente bien frecuentes. Por no hablar de aquellas en los que ni siquiera se motiva. No es este lugar para ahondar en este asunto. Pero si para decir que en medio de una cierta trivialización, por supuestamente obvio, de lo que la Constitución representa - debe representar- para el juez, discurren unas prácticas en las que el influjo de 
la norma fundamental, muchas veces, no se advierte fácilmente. El ideal garantista, como tal, no conoce punto de llegada. Pero, de haberlo, en hipótesis, estaríamos aún muy lejos de él.

Creo que en los jueces, en general, ha calado lo bastante la conciencia del reforzamiento del propio poder que se deriva de la Constitución vigente. No estoy seguro de que haya lo haya hecho de igual forma la idea de que ese poder solo tiene sentido como independencia de una determinada calidad y para un solo fin: dotar de eficacia a la jurisdicción - que es actividad del caso concreto- como función de garantía de derechos fundamentales. En esto, es decir, la garantía de los derechos fundamentales (prestación de un servicio público) desde la independencia (poder), se resuelve el papel constitucional de la jurisdicción.

\section{Acerca de los derechos sociales y su problemática justiciabilidad}

Para una concepción de los derechos como la que antes se ha ilustrado, los conocidos como derechos sociales — "derechos fundamentales sociales", al decir de Alexy - serían los más típicos derechos inexistentes o noderechos, por la notable precariedad de su tutela judicial.

Ahora bien, según se ha anticipado, fuertes razones de orden teórico autorizan a sostener que el enunciado constitucional del derecho lo constituye como tal derecho, es decir, le confiere existencia como expectativa de satisfacción normativamente sancionada y, por consiguiente, genera la correspondiente obligación para el legislador.

Como ha escrito Prieto Sanchís, «todos los enunciados constitucionales, por el mero hecho de serlo, han de ostentar algún contenido o núcleo indisponible para el legislador».

Es el caso de «los principios reconocidos en el Capítulo III" (del Título I de la Constitución Española), que es como ésta llama a los derechos de que aquí se trata, el Art. 53.3 de la misma es claro: su alegación ante la jurisdicción ordinaria solo podrá producirse «de acuerdo con lo que dispongan las leyes que los desarrollen». Ahora bien, el mismo texto fundamental prescribe que tales principios «informarán [...] la práctica judicial", lo que implica algo más que la mera no-indiferencia de su consagración: la producción de alguna clase de eficacia jurídica.

Desde la perspectiva que aquí interesa, la de la posible justiciabilidad de los derechos sociales, se ha objetado como obstáculo insalvable que su 
efectividad requiere una compleja mediación estatal (legislativa, presupuestaria, organizacional) en la que el juez no podría, en modo alguno, subrogarse o actuar por sustitución, en virtud del principio de separación de poderes.

Así, resulta que el ámbito del discurso en la materia se encuentra circunscrito por los límites representados, de un lado, por la ineludible trascendencia normativa de todo enunciado constitucional y la necesidad de tomarse en serio al legislador constituyente; $y$, de otra parte, por el obstáculo fáctico en que puede erigirse la falta de voluntad política del legislador ordinario de producir el correspondiente desarrollo constitucional.

La doctrina jurídica ha explorado ese territorio, con resultados de indudable interés desde el punto de vista de la jurisdicción, como han puesto de relieve Abramovich y Courtis en un detallado análisis.

Para empezar, es claro que ya no resulta posible sostener que exista algún tipo de derechos fundamentales que implique para el Estado la única exigencia de no hacer o de abstenerse de actuar. No hay derecho civil y político cuya garantía no obligue al Estado a predisponer recursos y medios de diversa índole, con la consiguiente repercusión presupuestaria. Por otra parte, hay violaciones de derechos sociales que tienen su origen en el incumplimiento de obligaciones negativas por parte del Estado, en especial la de no discriminar (Art. 14.1 CE). De modo que la diferencia entre esos derechos y los económicos, sociales y culturales debe ser relativizada, al tratarse de una cuestión más de grado que de naturaleza.

El resultado inmediato es que, al menos en el caso del primer grupo de derechos, los civiles y políticos, su contenido -en alguna medidaprestacional no representa un obstáculo a la intervención judicial.

El Art. $2^{\circ}$ del Pacto Internacional de Derechos Económicos, Sociales y Culturales (PIDESC) obliga a los Estados «a adoptar medidas [...] hasta el máximo de los recursos de que disponga para lograr progresivamente por todos los medios apropiados, inclusive en particular la adopción de medidas legislativas, la plena efectividad de los derechos aquí reconocidos». A partir de aquí, el ECOSOC ha declarado que si bien el logro de la plena efectividad de los derechos puede ser de realización progresiva, existen obligaciones con «efecto inmediato", como es la de garantizar que los derechos de que se trata se ejercerán sin discriminación y la de «adoptar medidas".

De donde resulta, que si ciertamente un masivo incumplimiento de un determinado deber estatal en materia de derechos económicos, socia- 
les y culturales sería con toda probabilidad judicialmente irremovible (se piensa en la jurisdicción no constitucional), puesto que implicaría, entre otras cosas, un defecto de ley ordinaria; en presencia de incumplimientos parciales, el citado precepto del Art. $2^{\circ}$ del PIDESC abre un evidente espacio a la intervención jurisdiccional.

Me refiero a la posibilidad de actuaciones inspiradas, aparte de en el principio de no discriminación, en el deber de progresividad y en la consiguiente obligación de no regresividad; en las que, demás, dada una razonada afirmación, por parte del demandante de justicia, de la existencia de indicios de incumplimiento, es claro que tendría que producirse una inversión del deber de probar en perjuicio de la instancia concernida. Y, acreditada la realidad de la discriminación, correspondería a esta última la carga, ahora, de justificar que la regresividad de la concreta medida sería el coste necesario de una política general significativa de un avance en la perspectiva de la generalidad de los derechos previstos en el PIDESC, según la interpretación dada a este por ECOSOC.

De lo que acaba de exponerse hay que extraer una consecuencia: el de los genéricamente conocidos como derechos sociales no es un campo vedado a la jurisdicción. Por el contrario, ésta se encuentra llamada en causa ya, al menos, de entrada, por la consagración normativa de los mismos como tales derechos ("principios» en el Art. 53.3 CE) y, después, porque allí donde se dé algún grado de desarrollo legal, la actividad interpretativa -inspirada en el principio pro homine - deberá estar reflexivamente orientada a dotar al derecho de que se trate del máximo de efectividad, para lo que pueden ser de indudable ayuda los criterios a que se ha hecho referencia y los que pueden recabarse de algunos casos especialmente significativos de la jurisprudencia del ETD.

Es bien sabido que el Tribunal Constitucional español no ha sido especialmente avanzado en el tratamiento de los derechos sociales; para lo que, por lo demás, es claro que tampoco corren los mejores tiempos. Pero también lo es que, en referencia a alguno de éstos, ha reconocido expresamente la existencia de un «núcleo o reducto indisponible por el legislador" (STC 37/1994). Algo, por otra parte, implícito en la propia calidad del enunciado constitucional como creación normativa de un derecho.

La jurisprudencia constitucional no puede ser indiferente para el juez que, cualquiera que fuera su sentido, no está legitimado para operar como si ésta no existiera. Ahora bien, cuando aquel encuentre motivos para la 
discrepancia y se halle en condiciones de argumentar de forma convincente con buen fundamento constitucional, deberá hacerlo. Creo que alimentar, con rigor y desde el caso concreto, una dialéctica de esa clase en el marco de la aplicación constitucional de la ley, es un deber exquisitamente judicial. El deber de tutela de los derechos fundamentales lleva implícita la obligación de estimular — con rigor y consistencia argumentaluna tensión permanente hacia la defensa/dilatación de sus límites; por la misma razón de que las prácticas político-administrativas suelen aquejar una marcada tendencia al redimensionamiento reductivo de los mismos. Proclamar ese deber no es postular una suerte de activismo voluntarista y gratuito, es contribuir a crear conciencia o a que no se pierda la memoria de que existe como tal deber para quienes - los jueces- tienen normativamente encomendada la garantía de unos derechos que cuentan con existencia constitucional-normativa. Solo se trata, como ha escrito García Herrera, «de mantener vigente la inspiración transformadora de la Constitución y de preservar la tensión que el propio texto alienta entre realidad y proyecto".

\section{En las nuevas fronteras de los derechos: un plus de judicialización inevitable}

Hay una esfera - semillero de serios problemas- de reciente emergencia desde el plano de la especulación ética al de la política del derecho y de la legislación. Es la esfera de la bioética, que ha acentuado el estatuto del cuerpo humano como zona de conflicto. El asunto tiene viejos antecedentes, como la prueba la cuestión del aborto. Pero ahora surge con renovados perfiles y con horizontes que cabe presumir amplios y muy abiertos a nuevos temas de discusión, que implicarán las correspondientes demandas de respuesta desde el derecho a cuestiones (la disposición del propio cuerpo, la identidad y la diferencia) que tienen que ver directamente con el derecho a la vida, a la salud, a la dignidad, en una perspectiva muchas veces inusual hasta la fecha.

En estos supuestos, como ha escrito Rodotà, se replantea con particular intensidad la opción entre dos modelos culturales de tratamiento: el de la jurisdicción y el de la legislación. Naturalmente no se trata de una opción radical y en términos excluyentes por uno de los integrantes del par, que no cabría en ningún caso. Ni el legislador puede dejar de sentirse 
interpelado y de responder a la demanda social; ni su respuesta, desde la generalidad de la ley, podrá prescindir de la mediación jurisprudencial.

El problema está en que, a juicio de este autor, las materias de que se trata, en buena medida abiertas y, en todo caso, muy conflictivas, no suelen ser susceptibles de un tipo tratamiento legislativo dirigido a solventar, en cada caso, el antagonismo de las posiciones, primando unilateral y definitivamente una de ellas, que sería la forma de pacificar normativamente el conflicto con carácter general.

Ahora bien, la naturaleza esencialmente pluralista de nuestras sociedades, que se refleja de forma emblemática en tales materias, tratándose de cuestiones extremadamente polémicas y con fuertes implicancias éticas, no se acomoda bien a esa clase de técnicas de intervención, que no median sino que cortan drásticamente.

La naturaleza y el estado de la cuestión en estos asuntos, intensamente debatidos en marcos sociales pluralistas, es lo que está llevando a optar por el modelo cultural de la jurisdicción, de la decisión caso por caso, en marcos de legalidad flexible o por principios, necesariamente abiertos por el propio carácter abierto y fluido de las cuestiones objeto de regulación.

Según el mismo Rodotà, la decisión judicial, en esta sociedad "caracterizada por un politeísmo de los valores [...] garantiza, además, una mayor adherencia a la situación concreta, evitando vigorizar la regla y permitiendo así una permanente adaptabilidad a una realidad en continua transformación, como es, precisamente, la que experimenta la incidencia de la innovación científica y tecnológica».

Salta a la vista que estamos en presencia de un, en gran medida, nuevo espacio para la jurisdicción, con fuerte implicación en materia de derechos fundamentales, y con serias exigencias en tema de responsabilidad y de bagaje cultural.

\section{Por una nueva geografía en la garantía de los derechos humanos fundamentales}

La pretensión de universalidad en la garantía de los derechos que expresa la Declaración de 1948, ha encontrado el mayor obstáculo a su realización en el viejo concepto de soberanía como suprema potestas superiorem non recognoscens, atributo de un poder legibus solutus. Semejante concepción del poder estatal, merced a la implantación —con todas 
las limitaciones que se quiera - del Estado de derecho, ha experimentado una relevante pérdida de vigencia en el orden jurídico interno, desde luego en los países del llamado "primer mundo", aunque no solo. Pero, por desgracia, la soberanía de "modelo Wesfalia" permanece con notable vigor en el mundo de las relaciones internacionales que, salvo en lo que se refiere a la economía, hoy globalizada, siguen dándose entre naciones soberanas al viejo estilo. Estas suelen ser llamativamente respetuosas de sus ámbitos de autonomía en la cuestión del tratamiento de los derechos humanos. Aquí, en la práctica, y a despecho de los pactos internacionales, prevalece en la mayor parte del mundo una perspectiva de derecho interno, que ha demostrado ser en muchísimas ocasiones garantía de no-derecho, de manos libres para poderes salvajes y de impunidad para sus políticas homicidas. De este modo, y todavía en la segunda mitad del siglo que concluye, hemos asistido al desarrollo a gran formato de una lacerante paradoja: mientras el Estado de derecho conocía un sensible afianzamiento en el orden estatal, la escenificación del modelo, presupuesta simbólicamente en la institucionalidad y el marco de relaciones derivadas de la Carta de la ONU, tiene traducción en lo que Rigaux ha descrito como una «caricatura de Estado de derecho».

En efecto, la idea de límite y contrapunto de la política democrática representada por la dimensión de derecho del Estado, bastante afianzada en el plano interno de los Estados constitucionales, está prácticamente ausente de las relaciones entre estados. En el espacio interestatal, reina el dogma de la soberanía, «máximo instrumento de la ideología imperialista del derecho contra el derecho internacional», según Kelsen.

La experiencia de lo que significa en términos prácticos ese terrible reinado, enriquecida por algunas emblemáticas actuaciones judiciales de tribunales españoles y por el perfil no menos emblemático de —miseria moral y jurídica de muchas de- las actitudes de oposición a las mismas, hace pertinente la evocación de la propuesta de avanzar hacia «la paz por medio del derecho", que el mismo Kelsen expresó dando este título una de sus obras. En la que desarrolla el proyecto kantiano de «despolitizar» las relaciones internacionales por la vía de la «juridificación".

Naturalmente, no es una propuesta planteada en términos de sustitución. Tan solo postula que en las relaciones interestatales se dé a la política lo que es de la política y al derecho la garantía de los derechos. Sobre todo, la garantía jurisdiccional, la garantía en última instancia. 
Del mismo modo que en la historia el Estado se constituye progresivamente a partir de la jurisdictio, $o$ «modo judicial de gobernar» (Anderson) y que la centralización de la función de aplicar la ley precedió a la centralización de la función de producirla, Kelsen entendió que la creación de una jurisdicción internacional podría desencadenar un proceso similar de articulación político-jurídica de la sociedad internacional, en torno a los valores del derecho como garantía de convivencia pacífica.

Mi perspectiva aquí es mucho más reducida. No cabe duda que el avance imparable de la globalización económica hacía una preocupante sociedad-mercado internacional sin Estado, hace cada vez más perentoria la necesidad de un proceso de constitucionalización e institucionalización a esa misma escala, si se quiere preservar con un mínimo de eficacia los derechos. Pero sin renunciar a ese ambicioso horizonte necesario, lo cierto es que hoy y ya se dispone de unos instrumentos de legalidad y jurisdicción que permiten un nivel de respuesta a las más graves violaciones de los derechos que no debería dejar de darse en todas las ocasiones que ello fuera posible.

En caso de los procesos judiciales seguidos en España y otros países contra las dictaduras del Cono Sur es paradigmático al respecto y pone de relieve que una parte del vacío de persecución de los crímenes de aquellas que se denunciaba, estaba siendo en la práctica una forma, siquiera implícita, de renuncia a la persecución, por la no utilización de instrumentos legales y procesales ya disponibles para las jurisdicciones nacionales.

En esa interesantísima fundamental experiencia en curso, que tiene estos días su punto álgido en la detención y posible extradición de Pinochet, y que está generando un consenso prácticamente universal, hay a mi juicio algo de anticipación más que simbólica - modesta si se quiere, pero cierta - de ese orden jurídico universal que con tanta urgencia se necesita. En tal consideración, debe ser objeto de reflexión en una triple perspectiva, que cabe concretar en tres afirmaciones.

La primera es que ha de quedar definitivamente claro que no habrá derechos suficientemente garantizados sino lo están, tanto en el ámbito internacional como en el orden interno, sobre todo frente a quienes se han manifestado como sus primeros y más acervos infractores, los propios Estados; y mientras el sistema de límites y las acciones de restauración y, en general, de tutela, no se encuentren jurídicamente predispuestos erga omnes, de forma rígida y eficaz, a salvo de cualquier derogación por razones de oportunidad política. En este punto, no hay duda de que 
la jurisdicción y la independencia judicial, tiene que jugar un papel esencial. Será la jurisdicción del país de que se trate, obviamente en primer término, cuando esté en condiciones de hacerlo con eficacia. Pero, en su defecto y en defecto de una instancia judicial internacional realmente operativa, y preventivamente, en cualquier caso, se impone dotar de eficacia al fuero universal del juez nacional, para que exista una auténtica alternativa a la impunidad de los crímenes de lesa humanidad, que ha estado siendo la regla y que tiene tantos partidarios. En la conocida fábula del molinero y Federico II, rememorada por Radbruch, la garantía de su derecho estaba en que hubiera «jueces en Berlín». Ahora, es más claro que nunca, solo puede radicar en la previsión cierta de que existirá un juez para cualquier crimen contra los derechos humanos, sea cual fuere el lugar donde se produzca. Lo que hasta aquí ha sido garantía de impunidad, debe traducirse en garantía judicial de tales derechos.

La segunda es que la preservación hacía el futuro de ese riquísimo pero frágil patrimonio que tiene adecuada expresión normativa en la Declaración Universal y en los textos complementarios, exige un urgente desarrollo legislativo internacional que se traduzca en la pronta publicación del Código penal de ese ámbito, en el que la ONU está desde hace tanto tiempo trabajando; y en la consiguiente puesta a punto de un verdadero Tribunal Penal Internacional realmente accesible a todas las víctimas de crímenes de lesa humanidad.

La tercera es que, no hay cabe engaño: la elaboración jurídico-cultural de los derechos humanos y su garantía, es una tarea permanente inacabada, incompatible con actitudes conformistas y burocráticas. Cierto que en marcos constitucionales no ha de ser cosa de aventureros y que no puede discurrir al margen de las reglas de la democracia política ni de las jurídicas del juego. Pero no es casualidad que, de Ihering a Bobbio, se haya hablado de ellas en términos de lucha, vocablo que en este contexto carece de cualquier connotación agresiva. Aquí lucha solo denota esfuerzo o, mejor, sobreesfuerzo constructivo y reconstructivo, tensión ideal, compromiso con los valores más altos del ordenamiento. Esto quiere decir también apertura cultural, porque el derecho no se nutre de su propia sustancia. Pues, como dice el viejo maestro de Turín en las líneas finales de su hermoso prólogo a Derecho y razón, el libro de Ferrajoli: «ni siquiera el más perfecto sistema del garantismo puede encontrar en sí mismo su propia garantía". 


\section{Bibliografía}

Abramovich, V. y Courtis, C., «Hacia la exigibilidad de los derechos económicos, sociales y culturales. Estándares internacionales y criterios de aplicación ante los tribunales locales», en: M. Abregú y C. Courtis (compiladores), La aplicación de los tratados sobre derechos humanos por los tribunales locales, Centro de Estudios Legales y sociales/ Ediciones del Puerto, Buenos Aires, 1997, p. 283 y ss. También en: Contextos. Revista crítica de Derecho social, No 1, 1997, p. 3 y ss. Alberti Rovira, E., "La protección judicial de los derechos y libertades», Barcelona, 1986, (versión mecanografiada).

Alexy, R., Teoría de los derechos fundamentales, Trad. de E. Garzón Valdés, Centro de Estudios Constitucionales, Madrid, 1993.

Anderson, P., Transiciones de la antigüedad al feudalismo, Trad. de S. Juliá, Siglo XXI, Madrid, 1979.

Andrés Ibáñez, P., «Impunidad y protección de los derechos humanos», en: El otro derecho, No 20, ILSA, Bogotá.

"La impunidad no es solo cuestión de hecho. Sobre la persecución en España de los crímenes de la dictadura militar argentina», en: Revista IIDH, Instituto Interamericano de Derechos Humanos, No 24, julio-diciembre de 1996.

"Contra las inmunidades del poder: una lucha que debe continuar", en: Revista Española de Derecho Administrativo, No 93, p. 5 y ss.

Atienza, M., "Sobre el control de la discrecionalidad administrativa. Comentarios a una polémica», en: Revista española de Derecho Administrativo, No 85 , p. 5 y ss.

"Virtudes judiciales», en: Claves de razón práctica, № 86 , octubre 1998 , p. 32 y ss.

Bobbio, N., El tiempo de los derechos, trad. de R. de Asís Roig, Editorial Sistema, Madrid, 1991.

Bonnanate, L., I doveri degli statu, Laterza, Roma-Bari, 1994.

Borré, Giuseppe, "Le scelte di Magistrature democratica», en: N. Rossi (ed.), Giudici e democrazia, Franco Angeli, Milán, 1994, p. 41 y ss. Calamandrei, P., Costituzione e leggi di Antigone. Scritti e discorsi politici, con notas introductorias de A. Galante Garrone y M. Cappelletti, La Nuova Italia Editrice, Florencia, 1996.

Capella, J. R., Los ciudadanos siervos, Trotta, Madrid, 1993.

Casamayor., Les juges, Editions du Seuil, París, 1978.

De Cabo Martin, C., La crisis del Estado Social, Ediciones PPU, Barcelona, 1986. 
«Estado social de derecho y ley general», en: Jueces para la Democracia. Información y debate, No 23, 3/1994.

De Giovine, A. y Dogliani, M., "Della democracia emancipante alla democracia senza qualitá?», en: Questione giustizia, No 2/1993, p. 321 y ss.

Delgado Barrios, J., «Los derechos y los jueces», (discurso leído por el Presidente del Tribunal Supremo y del Consejo General del Poder Judicial en la apertura del año judicial), Madrid, 1998.

De Lucas, J., El desafío de las fronteras. Derechos humanos y xenofobia frente a una sociedad plural, Ediciones Temas de Hoy, Madrid, 1994. "Globalización y derechos humanos», en: Jueces para la Democracia. Información y debate, No 33 , julio, 1998, p. 3 y ss.

Díaz, Elías, Estado de derecho y sociedad democrática, Taurus, Madrid, $9^{a}$ ed., 1998.

Estévez Araujo, J. A., La constitución como proceso y la desobediencia civil, Trotta, Madrid, 1994.

Fernández, T. R., De la arbitrariedad de la administración, Civitas, Madrid, 2a ed., 1997.

Ferrajoli, L., Derecho y razón. Teoría del galantismo penal, Trad. de P. Andrés Ibáńez, A. Ruiz Miguel, J. C. Bayón, J. Terradillos y R. Cantarero, Trotta, Madrid, 3a ed., 1998.

- «Derechos y garantías. La ley del más débil» (en preparación) por Trotta, Madrid.

Fioravanti, M., Los derechos fundamentales. Apuntes de historia de las constituciones, Trad. de M. Martínez Neira, Trotta, Madrid, 1996.

Garapon, A., Le gardien des promeses. Justice e democratie, Editions Odile Jacobs, París, 1996.

García de Enterría, E., La constitución como norma y el Tribunal Constitucional, Civitas, Madrid, 1981.

Democracia, jueces y control de la administración, Civitas, Madrid, 4a ed., 1998.

García Herrera, M. A., «Poder judicial y Estado social: legalidad y resistencia constitucional», en: P. Andrés Ibáñez (Ed.), Corrupción y Estado de derecho. El papel de la jurisdicción, Trotta, Madrid, 1996, p. 59 y ss.

"Estado en transformación y desformalización del derecho», en: P. Andrés Ibáñez (Ed.), Crisis del sistema político, criminalización de la vida pública e independencia judicial, CGPJ, Madrid, 1998, p. 183 y ss.

García Pascual, Cristina, «Doctrina contemporánea de derecho internacional», 1998, (versión mecanografiada). 
Guastini, R., Il giudice e la legge, Giappichelli, Turín, 1995.

Gozzi, G., "Per una teoria constituzionale della democrazia", en: G. Gozzi (Ed.), Democrazia, diritti, costituzione. I fondamenti costituzionali delle democrazie contemporanee, Il Mulino, Bolonia, 1997, p. 19 y ss.

Häberle, Peter, Le libertá fondamentali nello Estato costituzionale, La Nuova Italia Scientifica, Roma, 1993.

Haro Tecglen, Eduardo, Una frustración: los derechos del hombre, Ayma, Barcelona, 1969.

Kant, Inmanuel, La paz perpetua, Trad. de J. Abellán, Tecnos, Madrid, 1985.

Kelsen, Hans, La pace attraverso il diritto, Edizione de Luigi Ciaurro, Giappicheli Editore, Turín, 1990.

- Teoría general de las normas, Trad. de H. C. Delory Jacobs, Trilla, México.

Peces-Barba Martínez, G., (con la colaboración de R. de Asís Roig, C.R. Fernández Liesa y $\mathrm{A}$. Llamas Cascón), Curso de derechos fundamentales. Teoría general, Universidad Carlos III-Boletín Oficial del Estado, Madrid, 1995.

Peña Freire, A. M., La garantía en el Estado constitucional de derecho, Trotta, Madrid, 1997.

Pérez Luño, E., Derechos humanos. Estado de derecho y Constitución, Tecnos, Madrid, 1984.

Prieto Sanchís, L., Ley, principios, derechos, Instituto de Derechos Humanos «Bartolomé de las Casas», Universidad Carlos III, Madrid, 1998.

Radbruch, G., Introducción a la ciencia del derecho, Trad. de L. Recasens, prólogo de F. de los Ríos, Editorial Revista de Derecho Privado, Madrid, 1930.

Resta, E., Poteri e diritti, Giappichelli Editore, Turín, 1996.

Rodotà, S., "Modelli culturali e orizzonti della bioetica", en: Rodotà (ed.), Questioni di bioetica, Laterza, Roma-Bari, 1993, p. 421 y ss.

Ruiz Miguel, A., «Derechos liberales y derechos sociales», en: Doxa No 1516 , vol. II, p. 651 y ss.

Zagrebelsky, G., El derecho dúctil. Ley, derechos, justicia, Trad. de M. Gascón Abellán, epílogo de G. Peces-Barba, Trotta, Madrid, 1995.

Zolo, D., "La strategia della cittadinanza", en: D. Zolo (Ed.), La cittadinanza, appartenenza, identità, diritti, Laterza, Roma-Bari, 1994. 